\title{
BASTIAN, Till, Furchtbare Aerzte. Medizinische Verbrechen im Dritten Reich
}

Isabelle von Bueltzingsloewen

\section{OpenEdition}

\section{Journals}

Édition électronique

URL : http://journals.openedition.org/ifha/1540

DOI : $10.4000 /$ ifha. 1540

ISSN : 2198-8943

Éditeur

IFRA - Institut franco-allemand (sciences historiques et sociales)

\section{Référence électronique}

Isabelle von Bueltzingsloewen, «BASTIAN, Till, Furchtbare Aerzte. Medizinische Verbrechen im Dritten Reich », Revue de l'IFHA [En ligne], Date de recension, mis en ligne le 01 janvier 1997, consulté le 22 septembre 2020. URL : http://journals.openedition.org/ifha/1540 ; DOI : https://doi.org/10.4000/ifha. 1540

Ce document a été généré automatiquement le 22 septembre 2020.

(C)IFHA 


\title{
BASTIAN, Till, Furchtbare Aerzte. Medizinische Verbrechen im Dritten Reich
}

\author{
Isabelle von Bueltzingsloewen
}

Les crimes perpétrés par les médecins allemands à l'époque nazie ont, après de longues années de silence, suscité une multitude d'enquêtes menées par des historiens et par des médecins soucieux d'assumer l'héritage de leurs pères. Ce petit ouvrage publié dans la collection Beck'sche Reihe, rédigé par un spécialiste du nazisme, n'apporte pas de "révélation« sur ce sujet particulièrement sensible mais propose à un large public, dans un style d'une sobriété très pédagogique, une bonne synthèse des thèmes et des problèmes abordés par la recherche récente. Le livre se décompose en trois parties chronologiques. La première couvre une période qui s'étend de la fin du XIXe s. à l'avènement du nazisme. Sans adopter une perspective téléologique, l'auteur met l'accent sur quelques points qui permettent de mieux comprendre la séduction qu'a exercé l'idéologie nationale-socialiste sur la communauté médicale: la situation de monopole dans laquelle s'exerce la médecine depuis la fin du XIXe s., la scientifisation inachevée de la psychiatrie, l'affirmation du courant eugéniste, le développement de la médecine militaire au cours de la première guerre mondiale, enfin la crise idéologique que constitue la République de Weimar pour un corps médical majoritairement conservateur et nationaliste. Dans une seconde partie qui traite de la période 1933-1945, T.B. énumère les crimes auxquels de nombreux médecins allemands ont directement participé: la mise à l'écart des médecins juifs qui constituaient $11 \%$ des praticiens (8000 au total) et bien plus dans les grandes villes où ils jouissaient d'une position très enviée par leurs collègues »aryens«; la stérilisation, forme particulièrement agressive du darwinisme social, mise en oeuvre à partir de 1934: elle a probablement concerné 400000 personnes, sans doute davantage, entraînant la mort d'au moins 5000 d'entre elles et a particulièrement touché la communauté homosexuelle; l'action T4 et l'euthanasie sauvage qui visaient prioritairement les handicapés et les malades psychiatriques, enfin la sélection et les expériences menées dans les camps de concentration. Dans une dernière partie, l'auteur retrace les grandes 
lignes du procès de Nuremberg lors duquel furent jugés 23 accusés parmi lesquels 20 médecins; il souligne à juste titre que ce procès, minutieusement rapporté par Alexander Mitscherlich et Fred Mielke, a contribué à entretenir l'illusion d'une participation très marginale des médecins allemands aux exactions commises au nom de la science médicale et raciale, repoussant ainsi de plusieurs décennies la nécessaire autocritique de la communauté médicale.

Isabelle von BUELZINGSLOEWEN 